\title{
PERANAN BRIGADE MOBILE DALAM MEMPERTAHANKAN KEMERDEKAAN INDONESIA TAHUN 1946-1949
}

\author{
Agung Nugraha, Agus Mulyana, Achmad Iriyadi
}

Universitas Pendidikan Indonesia

\begin{abstract}
This research is entitled "The Role of Mobile Brigade Corps in Defending the Independence (19461949)". The researcher chose this problem because Mobile Brigade Corpse was the main pioneer in defending the independence. At the time of defending the independence, this Mobile Brigade Corps was not disbanded by Japan so that the Mobile Brigade Corps was really essential in defending Indonesia's independence. The main problem of this research is "How were the role of Mobile Brigade Corps in defending the independence?" The method used is the method of historical research by doing four steps of research which are heuristic, criticism, interpretation, and historiography. The technique used in data collection is literature study by reviewing the sources of literature relevant to the issues studied. Based on the research results, it can be explained that: First, before the independence, there is a change in the role performed by Mobile Brigade Corps. In the time of the Dutch colonialism, the role of the Mobile Brigade Corps was to maintain security and order but during the Japanese colonialism the role of Mobile Brigade Corpse is combat troops in helping Japan to face the Allies. Second, the early days of independence were marked by Japan's surrender to the Allies. After Japan surrendered to the Allies, all Japanese-formed military organizations were disbanded except the Mobile Brigade Corps. Under that condition, the Mobile Brigade Corpse joined the Indonesian republic. After joining the Indonesian republic, the role of the Mobile Brigade Corps was to disarm Japan along with the people. The disarmament results are then distributed to the struggle agencies. When entering the period of defending the independence, the role of the Mobile Brigade Corps is to fight against the threat of the Allies and the Netherlands. The resistance was carried out by the Mobile Brigade Corps along with other struggling agencies such as the People's Security Army.
\end{abstract}

Keywords: Mobile Brigade Corpse, Police, Brimob

\begin{abstract}
ABSTRAK
Penelitian ini mengkaji mengenai Peranan Brigade Mobile dalam mempertahankan Kemerdekaan pada kurun waktu tahun 1946-1949. Latar belakang peneliti mengambil permasalahan ini disebabkan karena Brigade Mobile merupakan pelopor utama dalam mempertahankan kemerdekaan. Pada masa mempertahankan kemerdekaan kesatuan Brigade Mobile ini tidak dibubarkan oleh Jepang sehingga kesatuan Mobile Brigade berperan dalam mempertahankan kemerdekaan Indonesia. Masalah utama yang diangkat dari skripsi ini adalah "Bagaiamana peranan Brigade Mobile dalam mempertahankan Kemerdekaan?" Metode yang digunakan adalah metode penelitian historis dengan melakukan empat langkah penelitian yaitu heuristik, kritik, interpretasi, dan historiografi. Hasil penelitian dapat dijelaskan diantaranya adalah Sebelum kemerdekaan terjadi perubahan pada peran yang dilakukan oleh Brigade Mobile. Pada masa pemerintah Belanda peran Brigade Mobile adalah menjaga keamanan dan ketertiban namun pada masa pendudukan Jepang peran Brigade Mobile dijadikan sebagai pasukan tempur dalam membantu Jepang untuk menghadapi Sekutu. Pada masa awal kemerdekaan ditandai dengan menyerahnya Jepang kepada Sekutu. Setelah Jepang menyerah kepada Sekutu semua organisasi militer bentukan Jepang dibubarkan kecuali Brigade Mobile. Dengan kondisi tersebut maka Brigade Mobile bergabung dengan republik Indonesia. Setelah bergabung dengan republik Indonesia maka peran yang dilakukan Brigade Mobile adalah melakukan pelucutan senjata Jepang bersama dengan rakyat. Memasuki masa mempertahankan kemerdekaan peran Brigade Mobile yaitu melakukan perlawanan terhadap ancaman Sekutu dan Belanda.
\end{abstract}

Kata Kunci: Brigade Mobile, Polisi, Brimob

Author correspondence

Email:nugrahagung27@gmail.com

Available online at http: // http://ejournal.upi.edu/index.php/factum 


\section{PENDAHULUAN}

Kepolisian Indonesia atau polri merupakan suatu lembaga penegak hukum yang bertugas untuk menciptakan suatu keamanan dan ketertiban. Agar terciptanya suatu stabilitas keamanan negara. Maka di dalam lembaga kepolisian terdapat suatu pasukan khusus guna menciptakan keamanan dan ketertiban negara. Pasukan tersebut adalah brimob atau brigade mobile. Brimob merupakan pasukan elite yang memiliki kemampuan lebih dibanding polisi reguler.

Apabila dilihat secara historis, pasukan Brimob di Indonesia sudah ada ketika pada masa penjajahan Belanda yang bernama Gewapende Polite dan kemudian digantikan oleh satuan lain yang bernama Veld Polite yang memiliki tugas yang sama. Tugas pasukan tersebut seperti bertindak sebagai unit reaksi cepat, menjaga ketertiban dan keamanan masyarakat, menghindari munculnya suasana yang memerlukan bantuan militer dan konsolidasi atas wilayah yang baru diperoleh.

Pada tahun 1944 pemerintah Jepang mulai membentuk suatu Polisi Istimewa (Tokobetsu Keisatsu Tai) atau yang lebih dikenal dengan Brimob. Tugas dari bentuknya Polisi Isimewa adalah pencegahan dan pembasmian kejahatankejahatan yang erat hubungannya dengan pertahanan Jepang di Indonesia (Suparno, 1971, Hlm.67). Hal tersebut sesuai dengan yang terdapat dalam Sejarah Perkembangan Kepolisian Indonesia

"Segala tindakan kepolisian diarahkan pada pemberantasan gerakan dan anasir anasir yang menentang pemerintah jepang. pemeriksaan terhadap pelaku kejahatan senantiasa diarahkan untuk megetahui usaha usaha provokasi, infiltrasi, sabotase. Pegawai polisi, terutama kader polisi, diberi latihan khusus tentang anti perang dan bahaya perang" (Djamin, 2006, hlm.86).

Pada masa pendudukan Jepang, Polisi Istimewa yang anggota pasukan berasal dari rakyat Indonesia, diberikan pelatihan dan pendidikan oleh pemerintah Jepang guna membantu Jepang dalam menghadapi perang melawan Sekutu dalam perang Asia Timur Raya. Dalam perang tersebut Jepang kalah, sehingga Jepang diperintahkan oleh Sekutu untuk membubarkan organisasi militer Jepang seperti pasukan tentara Peta (Pembela Tanah Air). Alasan Jepang membubarkan pasukan tentara Peta tersebut adalah berdasarkan hasil perjanjian Postdam yang menyatakan bahwa seluruh tanah jajahan negara-negara yang kalah dalam Perang Dunia II kepada negara- negara yang menang. (Moestopo, 1983, hlm.207).

Setelah Jepang menyerah kepada Sekutu dalam perang Asia Timur Raya, secara langsung Indonesia memproklamasikan kemerdekaan pada tanggal 17 Agustus 1945. Dengan adanya berita proklamasi kemerdekaan Indonesia, maka Polisi Istimewa segera bergabung menjadi bagian dari Republik Indonesia, Polisi Istimewa merupakan pasukan dengan senjata paling lengkap dibanding kesatuan lainnya. Ini terjadi karena senjata paling lengkap dibanding kesatuan lainnya. Ini terjadi karena senjata milik badan-badan militer bentukan Jepang seperti PETA telah dilucuti, sedangkan senjata dan pelengkapan Polisi Istimewa belum dilucuti. Ketika Jepang meminta mereka menyerahkan senjata, para anggota Polisi Istimewa menolak dan bahkan dengan tegas menggunakan perlengkapan tersebut untuk menghadapi Jepang dan Sekutu. Bukan hanya itu, Polisi Istimewa juga meruakan pelopor dalam berbagai upaya perlucutan senjata Jepang di Jawa Timur sehingga mereka bisa menyupai senjata kepada badan- badan perjuangan (Yauwerisa, 2013, hlm. 164).

Dengan adanya peranan yang dilakukan oleh anggota Polisi Istimewa dalam perjuangan bersama rakyat di Jawa Timur, maka dibentuklah organisasi Brigade Mobil pada tanggal 14 november 1946. Tujuan pokok dari pembentukan organisasi Mobile Brigade adalah untuk dijadikan sebagai tulang punggung bagi 
kepolisian umum yang kurang kuat persenjataan dan memberikan sumbangan yang besar bagi usaha pertahanan negara. Disamping itu organisasi Mobile Brigade memberikan bantuan kepada pemerintah daerah dalam menyelenggarakan keamanan dan ketentraman umum, khususnya turut mennegakan kedaulatan negara (Mabes, Polri, 1999, hlm, 77). Dalam pelaksanaan tugas, brigade mobil melakukannya secara represif atau langsung sedangkan tugas preventif atau pencegahan dilakukan oleh polisi Biasa (Kasdi, 2004, hlm.93).

Berdasarkan pemaparan di atas, maka peneliti pun ingin mengetahui lebih lanjut bagaimana peran dari kesatuan Brigade Mobile pada masa mempertahnakan kemerdekaan. Masalah utama yang diangkat dari penelitian ini adalah “ Bagaimanan Peranan Brigade Mobile dalam mempertahakan kemerdekaan? Berdasarkan permasalahan tersebut dapat diturunkan menjadi beberapa penelitian yaitu : (1) bagaimana kondisi Brigade Mobile sebelum kemerdekaan ? ; (2) Bagaimana kondisi Brigade Mobile pada masa awal kemerdekaan ? ; (3) Bagaimana Peran Brigade Mobile pada masa mempertahankan kemerdekaan?

\section{METODE PENELITIAN}

Dalam penelitian ini, peneliti menggunakan metode penelitian historis dengan langkah-langkah sebagai berikut:

1. Heuristik, atau pengumpulan sumber sejarah merupakan tahapan untuk mencari, menemukan dan mengumpulkan data, fakta dan sumber-sumber sejarah yang berkaitan dengan penelitian yang dikaji. Sumber-sumber sejarah itu bisa berupa dokumen, arsip, buku dan lain sebagainya. Menurut Langlois dan Seignobos (2015 hlm. 25) yang menyatakan bahwa sejarawan bekerja berdasarkan dokumen, dokumendokumen tersebut adalah jejak pikiran dan perbuatan yang telah ditinggalkan oleh orang-orang masa lampau. Peneliti pun mendapatkan buku dari berbagai perpustakaan seperti perpustakaan Universitas Pendidikan Indonesia (UPI), Perpustakaan Perguruan Tinggi Ilmu Kepolisian (PTIK), Perpustakaan Museum Polisi Republik Indonesia.. Selain itu buku yang digunakan oleh peneliti adalah buku milik koleksi pribadi dan hasil penelurusan internet. Adapun buku yang didapatkan adalah buku yang berjudul Sedjarah Perkembangan Angkatan Kepolisian Dari Zaman Klasik-Modern (1971) karya Suparno, Sejarah Perkembangan Kepolisian Angkatan Kepolisian (1995) karya Memet Tadumidja dan buku 10 November'45 Gelora Kepahlawanan Indonesia karya Barlan Setiadijaya.

2. Kritik Sumber, adalah proses untuk menguji dan mengkaji kebenaran rekaman dan peninggalan-peninggalan masa lampau dengan menganalisis secara kritis bukti-bukti dan data-data yang ada sehingga dapat disajikan dalam bentuk cerita sejarah (Ismaun, 2005 hlm. 35). Dalam proses kritik tersebut terbagi lagi menjadi dua tahap yaitu kritik eksternal dan krtik internal. Kritik eksternal adalah proses pengujian terhadap sumber sejarah dari aspek material seperti bahan dan bentuk sumber, umur dan bentuk sumber dan lain sebagainya (Ismaun, 2005 hlm. 50). Dalam proses kritik eksternal tersebut, penulis melakukan kritik terhadap surat kabar Warta Asia, sedangkan buku penulis melakukan kritik terhadap latar belakang penulisnya. Sedangkan kritik internal adalah proses pengujian tehadap sumber sejarah dari segi aspek isi atau konten sumber sejarah tersebut. Dalam kritik eksternal tersebut, peneliti lebih menekankan pada buku-buku yang digunakan. Peneliti pun membandingkan antara satu buku dengan sumber lainnya, 
tujuan dari uji banding tersebut adalah mencari kebenaran fakta yang terkandung di dalam sumber tersebut. Seperti misalnya dalam buku yang berjudul 10 November' 45 Gelora Kepahlawan Indonesia karya Barlan Setiadijaya dengan sumber lain yakni surat kabar Warta Indonesia yang terbit pada tanggal 5 Oktober 1945. Dari kedua literatur tersebut terdapat kesamaan yakni, mengenai penyerahan kekuasaan wilayah Jawa Timur dari panglima Jepang kepada Bangsa Indonesia. penyerahan tersebut dilakukan karena tidak terlepas dari peranan para anggota Polisi Istimewa yang merupakan cikal bakal menjadi brigade Mobil melakukan perlawanan terhadap tentara Jepang di Jawa Timur. Dengan adanya peranan tersebut maka pihak Jepang menyerahkan wilayah Jawa Timur kepada bangsa Indonesia.

3. Interpretasi, merupakan proses penafsiran terhadap sumber-sumber yang sudah dilalukan proses kritik secara internal maupun eksternal. Langkah yang dilakukan dalam tahap ini adalah mengolah, menyusun dan menafsirkan fakta yang telah teruji kebenarannya karena telah melalui tahap kritik kritik sumber. Faktafakta yang telah diproses kemudian dirangkai dan dihubungkan satu sama lain sehingga menjadi satu kesatuan yang utuh dimana peristiwa satu dengan lainnya menjadi sekaran dalam konteks peristiwa- peristiwa yang melingkupinya (Ismaun, 2005, hlm. 38).

4. Historiografi, atau penulisan ulang sejarah merupakan tahapan akhri dari proses penelitian sejarah. Menurut Abdurahman (2007, hlm.76) menyatakan bahwa historiografi merupakan cara penulisan, pemaparan atau pelaporan hasil penelitian sejarah yang dilakukan. Dalam tahap ini, peneliti merekonstruksi peristiwa mengenai pembentukan dan peranan Brigade Mobile pada masa mempertahankan kemerdekaan berdasarkan fakta- fakta yang telah didapatkan setelah melakukan tahapan- tahapan yang telah dilakukan dalam metode sejarah. Dimulai dari pencarian sumber-sumber, kemudian memverifikasinya, menafsirkan, hingga menyusunnya ke dalam suatu bentuk tulisan yang utuh.

\section{HASIL DAN PEMBAHASAN}

Secara resmi brimob didirikan pada tanggal 14 November 1946 , tetapi dilihat dari latar belakangnya atau dilihat dari sejarahnya, cikal bakal pasukan brimob sudah ada ketika masa pemerintahan Belanda. Pada tahun 1911 pemerintah Belanda melakukan reorganisasi dalam lembaga kepolisian, namun pada kenyataannya reorganiasi kepolisian ini belum cukup untuk menghadapi persoalan keamanan dengan memuaskan. Walaupun dilakukan reorganiasai sehingga menimbulkan keamanan dan ketertiban di kota- kota besar, tetapi kondisi keamanan di luar kota di luar kota masih belum stabil bahkan semakin memburuk (Mabes Polri, 1999, hlm. 26). Dalam perkembangannya Polisi bersenjata ini memiliki bersenjata tidak pandai memberantas kejahatankejahatan yang terjadi, karena tidak mempunyai keahlian dalam penyelidikan sehingga menimbulkankeamanan yang kacau, maka dibentuklah suatu korps Polisi lapangan Veld Polite yang menggantikan pasukan bersenjata. Pasukan lapangan ini dalam susunannya termasuk dalam bagian dari polisi Umum Algemeene Politie. Anggotanya berasal dari polisi bersenjata, kemudian anggota tersebut disatukan dan menjadi kesatuan Korps Polisi Lapangan (Bachtiar, 1994, hlm. 39).

Pada masa pemerintahan Jepang, Brimob sebelumnya merupakan Kesatuan Polisi Istimewa (Tokobetsu Keisatsu Tai). Tugas kepolisian (termasuk Polisi 
Istimewa) adalah menjaga keamanan dan ketertiban di wilayah Indonesia. Pada tahun 1944, pasukan Sekutu menyerang Jepang, maka Jepang mengerahkan personil kepolisian untuk keperluan perang. Pada bulan April, Pemerintah Jepang membentuk pasukan semi militer yang dikenal dengan nama Polisi Istimewa (Tokobetsu Keisatsu Tai) (Sulistyo, 2010, hlm. 49). Satuan Polisi Istimewa ini dibentuk disetiap daerah Pulau Jawa, yang berada dibawah perintah kepala Polisi karesidenan (dahulu wilayah administrasi di bawah administasi di bawah provinsi yang mengkordinir beberapa kabupaten.

Tidak lama setelah Jepang menyatakan menyerah tanpa syarat kepada Sekutu. Hal yang dilakukan oleh Jepang adalah membubarkan organisasi militer seperti PETA, Gyu-Gun dan Heiho. Alasan Jepang membubarkan organisasi militer tersebut karena Jepang harus menjaga keamanan ketika Sekutu datang ke Indonesia. Namun ada salah satu organisasi militer Jepang yang tidak dibubarkan oleh Jepang yaitu Polisi Istimewa (Tokobetsu Keisatsu Tai) yang berjumlah sekitar 100 (Yauwerissa, 2013, hlm 13). Tidak dibubarkanya Polisi Istimewa karena kesatuan Polisi Istimewa ini keberadaannya diakui oleh sekutu untuk menjaga keamanan dan ketertiban ketika Sekutu datang ke Indonesia. Dengan tidak dibubarkannya pasukan Polisi Istimewa, maka pasukan Polisi Istimewa membantu para pejuang untuk mendapatkan senjata. Tindakan yang dilakukan oleh rakyat dan Polisi Istimewa bertujuan untuk mempersiapkan senjata apabila Sekutu datang ke Indonesia, sehingga ketika nanti sekutu datang ke Indonesia, para pasukan Polisi Istimewa siap bertempur melawan sekutu. Terdapat beberapa cara untuk mendapatkan persenjataan Jepang dengan cara yaitu penyerahan senjata dari orang Jepang yang membelot ke pihak pihak Republik Indonesia dan pembelian dengan cara barter dengan serdadu Jepang atau luar negri (Imran, 2012, hlm.330).
Dengan adanya peran yang dilakukan oleh Polisi Istimewa, maka Kepolisian membentuk pasukan Mobile Brigade atau sekarang Brimob. Pembentukan pasukan Mobile Brigade Mobile ini merupakan tahap penyempurnaan organisasi kepolisian. Sejak zaman Jepang, kepolisian mempunyai pasukan polisi dengan tugas khusus, yang bernama Tokobetsu Keisatsutai atau Polisi Istimewa. Setelah Proklamasi kemerdekaan, mereka menjadi Polisi Istimewa atau Pasukan Polisi perjuangan yang dibentuk di tiap- tiap keresidenan. (Djamin dan Wulan, 2016, hlm.84). Untuk memperoleh persamaan susunan dan organisasi diantara pasukan ini, pimpinan kepolisian menganggap perlu mengadakan suatu reorganisasi. Tujuan dilakukan reorganisasi adalah agar kepolisian mencapai kesamaan dalam bentuk susunan, organisasi dan tata cara bekerja yang tidak ada sebelumnya.

Dengan adanya penataan kembali pasukan polisi Polisi Istimewa, maka pada tanggal 14 November 1946, wakil kepala Kepolisian Negara R. Soemarto diberi tugas oleh Soekanto untuk menyatukan pasukan Polisi Istimewa yang berada di setiap daerah menjadi satu dengan nama Mobile brigade atau Brimob. Hal ini diperkuat dengan adanya surat instruksi wakil kepala kepolisian Negara R. Soemarto, No. Pol : 12 / 78 / 91 tanggal 14 November 1946 (Yauwerissa, 2012, hlm. 98). Tanggal tersebut kemudian ditetapkan menjadi tanggal pendirian Brigade Mobil.

Dalam proses pembentukan korps Brigade Mobil. Kesatuan Mobile Brigade Besar ditingkat Provinsi, dibentuk menjadi tiga bagian yaitu, Mobile Brigade Besar Djawatan Kepolisian Pusat berada di Purwokerto, Mobile Brigade Besar Jawa Tengah berada di Surakarta dan Mobile Brigade Besar Jawa Timur berada di Sidoarjo keumudian pindah ke Malang. Setiap Mobile Brigade Besar (MBB) memiliki pasukan sekitar 400-600 orang dan dipimpin oleh seorang komandan 
Mobile Brigade Besar dengan pangkat komisaris Polisi. Secara administratif dan organisasi kesatuan Korps Mobile Brigade Mobil Besar ini bertanggung jawab kepada kepala kepolisian Djawatan Nasional atau kepala polisi Negara pusat.

Peran yang dilakukan oleh Brigade Mobile diawali ketika masa Agresi Militer Belanda I. Belanda melancarkan agresi militernya yang pertama pada 21 Juli 1947. Belanda berhasil melakukan pengepungan dengan menduduki daerah- daerah strategis sebagai usaha melemahkan kekuatan Republik Indonesia (Djamin dan Wulan, 2016, hlm. 87). Pasukan- pasukan Belanda bergerak dari Jakarta dan Bandung untuk menduduki Jawa Barat (tidak termasuk Banten) dan dari Surabaya untuk menduduki Madura dan Ujung Jawa Timur. Gerakan- gerakan pasukan yang lebih kecil mengamankan wilayah Semarang. Dengan demikian, Belanda menguasai semua menguasai pelabuhan di Jawa. Di sumatra, perkebunanperkebunan di sekitar Medan, instalasiinstalasi minyak dan Batubara di sekitar Palembang dan daerah Padang dikuasai Belanda (Djamin, 2006, hlm. 134).

Sampai berakhirnya Agresi Militer Belanda I, maka tercapai persetujuan Renville antara pemerinah Republik Indonesia dan Belanda tanggal 17 Januari 1948, terciptalah garis batas kekuasaan antara kedua belah pihak yang terkenal dengan Garis van Mook". Suatu garis buatan yang menghubungkan titik- titik terdepan pihak Belanda (Ricklef, 2008, hlm. 454). Garis van mook ini selanjutnya ditetapkan sebagai "garis status quo" antara daerah yang dikuasai RI dan daerah yang dikuasai Belanda. Di garis status quo ini ditempatkan Polisi Keamanan (PK) dengan tugas mencegah pelanggaran yang dilakukan oleh kedua pihak. Di daerah Sumatra tanggung jawab untuk menjaga garis status quo itu diserahkan pada polisi Republik Indonesia. Di Sumatra barat, misalnya dibentuk kesatuan penjagaan yang anggota terdiri dari pasukan Mobiele
Brigade Karesidenan Sumatra Barat, Polisi Umum dan pasukan Mobile Brigade Besar Sumatra. Pasukan ini disebut Polisi Keamanan (PK). Tugas Utama Polisi Keamanan (Djamin, 2006, hlm. 138).

1. Menjaga garis status quo yang telah disepakati antara Republik Indonesia dan Belanda

2. Mengawasi arus lalu- lintas barang, makanan termasuk ternak yang tidak boleh dibawa masuk ke daerah kekuasaan Belanda. Tetapi, barangbarang dagangan yang dibawa dari daerah kekuasaan Belanda, setelah diperiksa, diperbolehkan masuk ke daerah Republik Indonesia

3. Mengawasi mata- mata musuh yang merembes ke daerah Republik Indonesia

4. Melindungi Jiwa dan harta benda penduduk yang berada di dalam daerah Republik Indonesia.

Berdasarkan penjelasan diatas, dapat disimpulkan bahwa kepolisian pada masa agresi militer Belanda telah mengalami perubahan tugas dan wewnang. Tugas kepolisian adalah menjaga keamanan dan ketertiban umum di masyarakat agar terciptaakan stabilitas keamanan dalam negri. Namun karena terjadi serangan yang dilakukan oleh Belanda maka tugas kepolisian tidak hanya memilihkan keamanan saja tetapi harus menjadi bagian garda terdepan untuk mempertahankan kemerdekaan. Agar memudahkan tugasnya, kepolisian mengalami dimiliteriasi sehinga dapat mendapatkan tugas-tugas militer.

Pemberontakan PKI Madiun diawali dengan PKI berhasil memproklamasikan berdirinya Pemerintahan Soviet Republik Indonesia. Pemerinth Indonesia mengeluarkan pernyataan bahwa, gerakan PKI Muso di Madiun adalah tidak sah dan harus segera ditumpas. Pernyataan ini disamaikan oleh Presiden RI, kemudian diteruskan dengan perintah harian Jendral Sudirman yang berisi 1) Penunjukan 
Kolonel Gatot Subroto sebagai Gubernur Militer Jawa Tengah 2) Penunjukan Kolonel Soengkono sebagai Gubernur Militer Jawa Timur 3) Penugasan Kepada Brigade 13 untuk menyerbu Madiun dan menghancurkan PKI (Wiradiraharja, 1991, hlm. 55).

Pada tanggal 25 September 1948 ham o3.0o kesatuan Mobile Brigade, mulai bergerak meninggalkan kota Nganjuk dan langsung terlibat dalam pertempuran yang cukup sengit dengan pasukan pemberontak yang mendekati kota Nganjuk. Keesokan harinya kesatuan Mobile Brigade dapat memukul mundur pasukan pemberontak PKI/ Moeso dan merebut kembali desa Goyangan dan Desa Bagor. Setelah menduduki desa Bagor, kesatuan Mobile Brigade bergerak terus mengejar pasukan pemberontak yang mengunduurka diri dan kesauan Mobile Brigade Bermalam di Desa Wilangan (Danoekoesoemo, 1983, hlm. 171).

Pada 27 September 1948, kesatuan ketika pasukan bergerak ke Saradan, mereka mendapatkan perlawanan cukup berat dari FDR/ PKI. Namun, pada pukuln 14.30, Saradan berhasil dikuasai, meski dalam pertempuran tersebut dua orang anggota kompi Koesnadi terluka. Dari pertempuran tersebut dua orang anggota Kompi Koesnadi terluka. Dari pertempuran tersebut, pihak MBB berhasil merampas kaki senjata cungkir (senapan mesin buatan Jepang). Dari Saradan, perjalanan dilanjutkan ke Caruban dan bermalam di sana. Pada pukul 05.00, FDR/ PKI menyerang pasukan MBB yang berada di Caruban. Pertempuran berlangsung singkat karena jumlah personil MBB lebih banyak daripada pasukan FDR. PKI. Selanjutnya, mereka menuju ke Kota Madiun tanpa perlawanan. Setelah memasuki kota Madiun, pasukan MBB langsung membebaskan tahanan-tahanan FDR/PKI yang berada di Nglames dan Sekitar Rejoagung. Berdasarkan perintah Kolonel Gatot Subroto, pengejaran terhadap sisia FDR/ PKI dilanjutkan hingga ke Ponorogo. Pengejaran FDR/ PKI dimulai dari kota Madiun menuju ke desa Kanigoro-pagotan-Nguteran-DlopoKanten. Di Desa Kanten, pasukan MBB dibagi menjadi dua. Sebagian menuju ke arah selatan kota ponorogo dapat dikuasai tanpa mendapatkan kesulitan yang berarti. (Yauwerisa, 2012, hlm. 138).

Pada tanggal 31 Oktober 1948, Musso tewas saat berupaya melarikan diri, sehingga Musomengakhirikarirnyasebagai pemimpin PKI yang hanya berlangsung selama delapan puluh hari. Amir dan segerombolan tentara yang berjumlah 300 orang ditangkap oleh Pasukan Siliwangi pada 1 Desember. Amir dibunuh bersama para pemimpin terkemuka PKI lainnya. Dalam aksi-aksi penangkapan yang dilakukan setelah pemberontakan madiun tersebut, sekitar 35.000 orang ditangkap (Ricklef, 2008, hlm.482). Dengan ditangkap dan tembaknya tokoh-tokoh PKI yang terlibat dalam pemberontakan PKI Madiun 1948, kemudian terjadilah Agresi Militer Belanda II. Maka semua pasukan Republik Indonesia segera dipersiapkan menghadapi Belanda, sehinggga semua kekuatan pasukan Republik Indonesia di alihkan untk melawan serangan- serangan Belanda.

Setelah berakhirnya pemberontakan PKI Madiun, maka terjadilah Agresi Militer Belanda II. Pasukan Belanda melakukan serangannya pada 19 Desember 1948 yang diawali dengan serangan terhadap Yogyakarta sebagai ibukota Indonesia. pada saat aksi serangan Belanda ke Yogyakarta itu sering disebut dengan Agresi Militer Belanda ke II. Agresi Militer Belanda II dilatarbelakangi oleh aksi saling tuduh- menuduh antara Indonesia dengan Bealnda. Belanda beranggapan bahwa Indonesia tidak mematuhi persetujuan gencatan senjata. sedangkan Indonesia menuduh bahwa Belanda berupaya untuk mengambil alih seluruh wilayah Republik Indonesia. Menurut Mulyono (2008, hlm. 201) pada tanggal 18 Desember 1948 pada pukul 11.30 malam, Belanda memberitahu 
kepada Komisi Tiga Negara (KTN) bahwa persetujuan gencatan senjata dibatalkan oleh pihak Belanda. Pembatalan tersebut diberitahukan kepada sekretaris delegasi Republik Indonesia yang masih ada di Jakarta, baik KTN maupun delegasi Indonesia yang ada di Jakarta tidak bisa menghubungi pemerintah Indonesia, hal itu disebabkan karena pesan kawat Jakarta dan Yogyakarta sudah terputus.

Sementara itu di Jawa Timur, Belanda bergerak menerobos garis pertahanan Republik Indonesia sepanjang garis status quo. Kesatuan-kesatuan Kepolisian terutama dari Mobile Brigade yang menjaga garis status quo sebagai polisi keamanan segera terlibat dalam pertempuran dengan puhak Belanda. Dengan adanya pertempuran tersebut, mengakibatkan banyak jatuh korban pada pihak kepolisian. Kesatuan Kepolisian dari Mobile Brigade Karesidenan Surabaya di bawah Pimpinan Inspektur Polisi II Soetjipto Danoekoesoemo, memusatkan kekuatannya di Mojoagung. Pada tanggal 12 Januari 1949 dilakukan serangan terhadap kota Jombang, yang berhasil didudukinya untuk bebrapa jam. Pada tanggal 14 Januari 1949 Belanda melakukan serangan terhadap kota Jombang Selatan, sertaberjasil menduduki Pare, Belanda meneruskan gerakannya ke Jurusan Kediri.

Kesatuan- kesatuan Mobile Brigade Karesidenan Surabaya terus - menerus melakukan serangan terhadap pos pertahanan Belanda di Tunggorono, sembung cukir, ceweng dan serangan umum atas kota Jombang. Kesatuan Polisian dari Mobile Brigade Besar Jawa Timur di bawah pimpinan Komisaris Polisi Moehammad Jasin pada waktu Yogyakarta diserang Belanda, masih tersebar di beberapa tempat dan markas komandonya berada di Madiun. Setelah kota itu direbut kembali dari kaum pemberontak PKI. Sedangkan Belanda menyerang Madiun, markas komando Mobile brigade Jawa Timur telah dipindahkan ke perkebunan
Kopi di Komplek Gunung Wilis (Tanumidjaja, 1995, hlm. 59-60).

Kompi I dari Batalyon I Mobile Brigade Besar (MBB) Jawa Timur yang ditempatkan di daerah Malang di bawah pimpinan Paimo di samping menjaga garis demarkasi sebagai polisi keamanan, juga secara gerilya menyusup ke kota Malang dan melakukan pengacauan di dalam kota. Batalyon III MBB Jawa Timur yang ditempatkan di daerah Pinirigi di bawah pimpinan Pembantu Inspektur Polisi M. Sukari menyerang pertahanan Belanda di kota Ponorogo secara frontal. Tetapi tidak berhasil merebut kota itu. Pasukan tersebut kemudian mengundurkan diri ke jurusan selatan Ponorogo. Selanjutnya melakukan "Long March" ke daerah Besuki. Setelah sampai di Jember terjadi pertenpuran sengit dengan pihak Belanda sehingga mengakibatkan 9 orang anggotanya gugur. Ketika tiba di daerah basis gerilya di daerah Bondowoso bersama-sama dengan kesatuan-kesatuan TNI meneruskan perlawananna terhadap Belanda secara gerilya (Djamin, 2006, hlm.156). Batalyon I dan II dari Mobile Brigade Besar Jawa Timur di bawah pimpinan Komisaris Polisi II Moehammad Jasin tetap bertahan di Madiun, mempertahankan sektor Madiun Timur secara gerilya. Meskipun Belanda berkali-kali melakukan pembersihan di sektor Madiun, namun tidak berhasil berkat adanya bantuan dari rakyat (Mabes Polri, 1999, hlm. 71).

Tentara Belanda terus melakukan aksi serangan ke Yogyakarta, serangan tersebut harus segera dihentikan dan Indonesia harus segera merebut kembali ibukota Yogyakarta. Masyarakat, tentara, polisi dan para pejuang pun harus memikirkan bagaimana cara mematahkan seranganserangan yang dilakukan oleh pasukan Belanda. kepolisian mengirimkan kesatuan Mobile Brigade dalam melakukan serangan umum 1 maret 1949. Pasukan Mobrig tersebut dibagi menjadi dua kelompok. Kelompok I berkekuatan kurang lebih 100 orang langsung di bawah pimpinan 
Subroto Darsoprayitno berkedudukan Dukuh Manulis, Kelurahan Sumber Sari Kecamatan Moyudan. Kelompok II yang berkekuatan kurang lebih kurang lebh 100 orang dipimpin oleh M. Ayaiman berkedudukan di Kelurahan Ngijon Kecamatan Moyudan Yogyakarta. Dalam melakukan serangan tersebut, pasukan yang telah dibagi menjadi dua kelimpok menyerang pasukan Belanda melalui tiga arah. Dari arah barat kompi Mobile Brigade di bawah pimpinan Subroto Darsiprayitno berkedudukan di Manulis, Sumbersari, Moyudan bergerak menuju kota Yogyakarta. Kompi ini memperkuat markas komando Subwherkeise 103 A pimpinan H.N. Sumual Dari arah Selatan kompi MBB-DKN terdiri dari Seksi Kompi Johan Suparno yang bermarkas di sekitar Kotagede dan kompi kecil pasukan Musiman yang bermarkas di Ganjuran Bantul bergerak melalui jalan desa masuk kota Yogyakarta. Kompi ini memperkuat Subwherkeise 102 pimpinan Mayor Sardjono. Dari arah utara kompi polisi Pimpinan Sumarjan yang berkedudukan di Rejondan, Sleman menuju Yogyakarta untuk memperkuat SWK 104 pimpinan Mayor Soekarso (Seskoad, 1990, hlm.227)

Menurut Djamin (2006, hlm. 163-164) Pasukan mobile Brigade Daerah Istimewa Yogyakarta, yang terlibat langsung dalam serangan Umum 1 Maret 1949 adalah pasukan kelompok II dibawah pimpinan M. Ayatiman, ditambah dengan 1 regu dengan kelompok I dibawah pimpinan M. Sarjono. Pasukan Kelompok II dibagi dalam 3 seksi, masing- masing dipimpin oleh Agen Polisi I Jilian, Ajun Polisi I Jihan, Agen Polisi I langdung Harsono dan Ajun Polisi I Sugiyo. Kompi Ayatiman bergerak menuju Lempuyangan. Mereka bertemu dengan pasukan Belanda yang bergerak dari daerah Sosrowijayan ke arah timur. Dalam kontak senjata yang terjadi antara kedua pasukan itu, soernag anggota kompi ayatiman gugur. Akan tetapi, kompi ini tetap mempertahankan lempuyangan sampai ke bagian Barat jalan Malioboro dari serangan musuh. Di tempat lain, kompi Subroto berkekuatan dua peleton yang masing-masing dipimpin oleh Sugiyo dan Jilan melancarkan serangan terhadap kedudukan du Patuk. Pasukan Belanda tidak mampu bertahan dan mengundurkandiri. Selanjutnya, daerah Patuk dikepung oleh kompi subroto. Kedudukan Belanda di Pojok Benteng Timur diserang oleh Kompi Dhohan Suparni. Serangan itu gagal karena pertahanan Belanda di tempat ini sangat kuat.

Selain pasukan Mobile Brigade, anggota kepolisian yang terlibat dalam Serangan Umum 1 Maret 1949 adalah Polisi Pelajar Pertempuran ( $\left.\mathrm{P}_{3}\right)$. Anggota kepolsian tersebut yang masih mengenyam pendidikan kepolisian, karena dalam situasi peperangan maka mereka harus ikur terjun dalam peperangan mempertahankan kemerdekaan Indonesia. Menurut Rahmawati (2015, hlm.11) pada Serangan Umum 1 Maret 1949, pasukan Polisi Pelajar Pertempuran ( $\mathrm{P}_{3}$ ) dibagi menjadi tiga kelompok yaitu, seksi II Agen Polisi Kairun, Seksi Agen Polisi Supardan dan Seksi Agen Polisi Sukidjo. Salah satu anggota Kepolisian dari Seksi II yang bernama M.A. Tari bersama temannya bertugas untuk menyerang Pos Belanda yang berada di sebelah timur pojok Benteng Wetan. Seksi II Agen Polisi Supardan mendapatkan tugas ke Karangkajen dan sebagian memerkuat pasukan yang ada di pojok Benteng Wetan. Seksi Ajun Polisi Sukidjo (Seksi Senjata Berat) mendapat tugas ke Pleret. Sesuai dengan instruksi dari Mayor Sardjono, Inspektur Polisi II Johan Soeparno pada tanggal 28 Februari 1949 mengadakan breifing atau pengarahan kepada semua pasukannya. Briefing dilaksanakan pada pukul 16.0o di Markas Besar Banyakan Yogyakarta.

Setelah semua persiapan matang, maka serangan pun akan dilakukan. Pada tanggal 1 Maret 1949 pasukan Polisi Pelajar 
Pertempuran mulai mempersiapkan diriya untuk memulai serangan. Pada jam 06.0o pasukan Polisi Perjuangan pun mengambil posisi untuk bergerak serentak untuk melakukanpenyerangankekotaYogyakarta dari berbagai penjuru. Pasukan yang dipimpin oleh M.A. Tari mencoba untuk menyerang tangsi tangsi Belanda. namun karena pasukan M.A. Tari itu lebih sedikit dibandingkan dengan pasukan Belanda, maka mereka menarik diri ke markas Polisi Pelajar Pertempura di Banyakan. Selain itu pasukan Seksi Kairan dan Seksi Supardal harus mengundurkan diri ke daerah Pojok Benteng Wetan Yogyakarta. Mundurnya pasukan Polisi Pelajar Pertempuran ke daerah tersebut membuka peluang bagi pasukan Belanda untuk masuk ke Kotagede. Akibat invasi yang terus dilakukan oleh pasukan Belanda, kekuatan pasukan Polisi Pelajar Pertempuran menjadi melemah sehingga komandan Djohan Soeparno menginstruksikan untuk terus mengundurkan diri. Pada akhirnya pasukan Polisi Pelajar berhasil meloloskan diri dari cengkraman serangan musuh dan tidak ada korban jiwa atas penyerangan pasukan Belanda tersebut (Rahmawati, 2015, hlm. 12-13).

\section{SIMPULAN}

Berdasarkan beberapa penjelasan di atas maka maka dapat disimpulkan bahwa: Pertama, Kesatuan Brigade Mobil sudah ada ketika sebelum kemerdekaan tepatnya pada masa pemerintahan Hindia Belanda yang bernama Polisi Bersenjata atau Gewante Polite. Pembentukan Polisi Bersenjata tidak terlepas dari kondisi keamanan dan ketertiban di daerah yang semakin memburuk. Namun dalam perjalannya, Pasukan Polisi bersenjata ini tidak dapat menjaga keamanan dan ketertiban. Dengan adanya kondisi tersebut maka pemerintah Belanda membentuk kesatuan Polisi Lapangan Veld Polite sebagai pengganti kesatuan Polisi Bersenjata.
Pada tahun 1942 Belanda menyerah kepada Jepang, sehingga Jepang menguasai wilayah Indonesia. Pemerintah Jepang membentuk pasukan yang bernama Polisi Istimewa (Tokobetsu Kesiatsu Tai) atau sekarang disebut Brigade Mobile. Pembentukan tersebut tidak terlepas dari kondisi Jepang yang mulai terdesak oleh serangan Sekutu. Pasukan Polisi Istimewa merupakan unit pasukan yang dilatih secara khusus dan sewaktu- waktu turun di medang Perang. Satuan Polisi Istimewa ini dibentuk disetiap daerah Pulau Jawa yang berada di bawah perintah Polisi Karesidenan. Setelah Jepang menyatakan menyerah kepada Sekutu dan Kemerdekaan Indonesia diproklamasikan, Satuan Polisi Istimewa tidak dibubarkan oleh Jepang dan segera bergabung menjadi bagian dari Republik Indonesia.

Kedua, Brigade Mobile pada masa awal kemerdekaandimulaiketikaPolisiIstimewa atau Brigade Mobile bergabung menjadi bagian dari Republik Indonesia. Pasukan Polisi Istimewa memiliki persenjata paling lengkap dibandingkan dengan kesatuan lainya. Hal ini terjadi karena senjata milik badan badan militer bentukan Jepang seperti PETA telah dilucuti, sedangkan senjata dan pelengkapan Polisi Istimewa belum dilucuti. Pada saat Jepang meminta kepada Pasukan Polisi Istimewa untuk menyerahkan senjata, para anggota Polisi Istimewa menolak dan bahkan dengan tegas menggunakan perlengkapan tersebut untuk menghadapi Sekutu. Selain itu juga, Polisi Istimewa merupakan pelopor dalam berbagai upaya perlucutan senjata Jepang di Jawa Timur. Dengan adanya peranan yang dilakukan Polisi Istimewa tersebut, maka wakil Kepolisian memberikan usul untuk dibentuklah kesatuan Mobile Brigade atau sekarang disebut Brigade Mobil.

Ketiga, Brigade Mobile pada masa mempertahankan kemerdekaan dapat dilihat dari adanya peranan yang dilakukan oleh Brigade Mobile dalam 
mempertahankan kemerdekaan dari ancaman Sekutu dan Belanda. Brigade Mobile bekerjasama dengan pasukan bersenjata lainnya seperti Tentara Keamanan Rakyat, laskar- laskar dan masyarakat untuk bertempur dalam mempertahankan kemerdekaan dari ancaman Sekutu dan Belanda. Dengan adanya peranan Brigade Mobil dalam mempertahankan kemerdekaan, terjadi perubahan pada peran dari kesatuan Brigade Mobil. Peran Brigade Mobil adalah menjaga keamanan dan ketertiban umum di masyarakat agar terciptakan stabilitas keamanan dalam negri. Namun karena terjadi serangan yang dilakukan oleh Belanda, maka peran Brigade Mobile tidak hanya memilihkan keamanan saja tetapi harus menjadi bagian garda terdepan untuk mempertahankan kemerdekaan.

\section{DAFTAR PUSTAKA}

Abdurahmman, D. (2007). Metodologi Penelitian Sejarah. Yogyakarta : ArRuzz Media. (Halaman 76).

Bachtiar, H. W. (1994). Ilmu Kepolisian Suatu Cabang Imu Pengetahuan yang baru.

Jakarta : PT. Grasindo. (Halaman 39).

Danoekoesoemo. (1983). Sejarah perjoangan Polisi Surabaya 1945-1949. Surabaya :

Panitya Pembuatan Buku Sejarah Perjoangan Polisi Istimewa Surabaya.

(Halaman 171).

Djamin A. (2006). Sejarah Perkembangan Kepolisian Di Indonesia Dari Zaman Kuno Sampai Sekarang. Jakarta : Markas Besar Kepolisian Republik Indonesia (Halaman 86,134,138 dan163-164).

Djamin, A dan Wulan, A. (2016). Jendral Polisi R.Soekanto Tjokrodiatmodjo. Jakarta : Kompas Media Nusantara. (Halaman 84 dan 87).
Imran A. Dan Iskandar. (2012). Indonesia Dalam Arus Sejarah Jilid 6 Perang Dan Revolusi. Jakarta : PT Ichtiar Baru van Hoeve. (Halaman 330).

Ismaun. (2005). Sejarah Sebagai Ilmu dan Wahana Pendidikan. Bandung : Historia Utama Press. (Halaman 35,38 dan 50).

Kasdi, A. (2004). 50 Tahun Pusdik Brimob Watukosek Pasuruan Jawa Timur. Jakarta: Unesa University Press. (Halaman 93).

Langlois, C.V dan Seignobos, C. (2015). Pengantar Ilmu Sejarah. Diterjemahkan oleh H. Supriyanto Abdullah. Yogyakarta : Indoliterasi. (Halaman 25).

Mabes Polri. (1999). Sejarah Kepolisian Di Indonesia Cetakan Pertama. Jakarta :

Mabes Polri. (Halaman 77 dan 26).

Moestopo. (1983). Bunga Rampai Perjuangan Dan pengorbanan. Markas Besar Legiun Veteran RI : Jakarta. (Halaman 207).

Mulyono. (2008). Pertempuran 10 November 1945 Kesaksian Dan Pengalaman

Seorang Aktor Sejarah. Jakarta : Visimedia. (Halaman 201).

Rahmawati, N. (2016). "Peranan Polisi Pelajar Pertempuran ( $\left.\mathrm{P}_{3}\right)$ dalam Perang

Kemerdekaan II di Yogyakarta Tahun 1948-1949”. Journal Mozaik Sejarah Indonesia : E-Journal Ilmu Sejarah, 2. (3). Hlm. 11-15. (Halaman 11-13).

Ricklefs, M. C. (2008). Sejarah Indonesia Modern 1200-2009. Jakarta : PT Serambi

Ilmu Semesta. (Halaman 454 dan 482).

Seskoad. (1990). Serangan Umum 1 Maret di Yogyakarta : Latar Belakang dan

Pengaruhnya. Cetakan II. Jakarta : Lamtorogung Persada. (Halaman. 227). 
Sulistyo, H. (2010). Derap Langkah Polri. Wiradiharja, Agus. (1991). Peranan POLRI Jakarta : Grafika Indah. (Halaman 49). Dalam Menumpas Pemberontakan

Suparno. (1971). Sedjarah Perkembangan PKI di Madiun Tahun 1948. Jakarta : Kepolisian Dari Zaman Klasik-Modern. Sub Direktorat Sejarah Markas Besar Jakarta : Pusat Sedjarah ABRI. (Halaman 67).

Tanumidjaja, M. (1995). Sedjarah Perkembangan Angkatan Kepolisian. Jakarta : Pusat Sedjarah ABRI. (Halaman 59-60). 